\title{
Corrigendum
}

\section{The association between implementation of second-tier prevention practices and CLABSI incidence: A national survey_CORRIGENDUM}

In the above mentioned article by Ben-David et $\mathrm{al}^{1}$, author Jalal Tarabeia's affiliation was originally incomplete due to an error made during the proof revision process. The affiliation has since been corrected. The publisher apologizes for the error.

\section{REFERENCE}

1. Ben-David D, Vaturi A, Solter E, Temkin E, Carmeli Y, Schwaber MJ, Israel CLABSI Prevention Working Group. The association between implementation of second-tier prevention practices and CLABSI incidence: A national survey. Infect Control Hosp Epidemiol 2019;40: 1094-1099. 